\title{
TÉCNICA DE CRUZAMENTOS CONTROLADOS EM EUPHORBIA HETEROPHYLLA L.(1)
}

\author{
LEANDRO VARGAS ${ }^{(2)}$, ALUÍZIO BORÉM ${ }^{(3)} \&$ ANTONIO ALBERTO DA SILVA $^{(3)}$
}

\begin{abstract}
RESUMO
O leiteiro, Euphorbia heterophylla L., é uma planta daninha comum no Sul, no Sudeste e no Centro-Oeste do Brasil. Seu controle químico é realizado principalmente com herbicidas que agem inibindo a enzima acetolactato sintase. Contudo, nos últimos anos, vêm sendo observados genótipos resistentes em diversas lavouras da região Sul. Até o momento, não se realizaram estudos sobre as características genéticas de tal resistência. Este trabalho teve como objetivo descrever uma técnica de cruzamento controlado em Euphorbia heterophylla L., para viabilizar futuros estudos genéticos. Efetuaram-se hibridações controladas em diversas fases do desenvolvimento do botão floral das plantas. As polinizações e emasculações realizadas no estádio 1(quando as flores femininas apresentam estiletes separados, eretos e com coloração avermelhada, e ovário incluso no ciátio) produzem grande número de ciátios com uma ou duas sementes e raras com três. As realizadas no estádio 2 (momento em que os estiletes estão separados e pouco reflexos sobre o ciátio com alteração da coloração avermelhada para branca, com a extremidade bifurcada, e ovário ainda incluso no ciátio) ou acima deste, garantiram o sucesso dos cruzamentos com boa produção de sementes.
\end{abstract}

Termos de indexação: hibridação, Euphorbia heterophylla L., biologia floral.

\section{ABSTRACT \\ CROSSING TECHNIQUE IN EUPHORBIA HETEROPHYLLA L.}

Euphorbia heterophylla L. is a common weed in the South, Southeast, and Central West portions of Brazil. Chemical control is mainly done with herbicides that inhibit the

\footnotetext{
(1) Recebido para publicação em 22 de maio e aceito em 9 de dezembro de 1998.

(2) Doutorando em Fitotecnia, Universidade Federal de Viçosa, Viçosa (MG).

(3) Departamento de Fitotecnia, Universidade Federal de Viçosa - Câmpus Universitário, 36571-000 Viçosa (MG).
} 
enzyme Acetolactate synthase. However, resistant individuals have being observed in several farms of the South Region. There is no information about the genetic control of such resistance. The present work was aimed to study the hybridization technique in Euphorbia heterophylla L. It was studied the anatomy and the organogenesis of different individuals. Controlled emasculations and pollinations carried out in the stage 1 (when the flowers present separate styles, erect and red, and ovary inside of the cyathium) produce great number of cyathium with one or two seeds and rarely three. The hybridizations carried out in the stage 2 (when the styles are separate and little reflex on the cyathium, turning from red to white, with the forked extremity, and ovary still included in the cyathium) or beyond this, do not affect the success of the hybridizations and the number of seeds.

Index terms: hybridization, Euphorbia heterophylla L., flower biology.

\section{INTRODUÇÃO}

O leiteiro, Euphorbia heterophylla L., é uma planta daninha comum no Sul, no Sudeste e no Centro-Oeste do Brasil. É uma espécie nativa nas regiões tropicais e subtropicais das Américas (Cronquist, 1981). Apresenta ciclo anual, porte médio de 40-60 $\mathrm{cm}$ e é altamente competitiva, com rápido crescimento e multiplicação. O caule é simples ou ramificado, com nodificações em intervalos regulares. As folhas, alternas, opostas ou verticiladas, ocorrem tanto no caule como nos ramos, com uma concentração na parte final dos ramos, abaixo da inflorescência (Cronquist, 1981; Kissmann \& Groth, 1992).

A flor é uma estrutura bissexual chamada ciátio (Cronquist, 1981). Na inflorescência, localizada na parte terminal do caule e dos ramos, desenvolvem-se conjuntos de ciátios, ou seja, invólucros obovóides com cerca de $2,5 \mathrm{~mm}$ de comprimento, formados por brácteas fusionadas, abertos na parte superior. Cada ciátio abriga 30 a 40 flores masculinas e apenas uma feminina, constituída pelo ovário, coroado por estiletes fendidos até a metade e apoiada sobre grosso pedicelo que, após a fecundação, se alonga posicionando o fruto de forma pendente ao lado do invólucro. A flor masculina é formada por um estame, articulado no pedicelo. Os estames circundam a flor feminina (Kissmann \& Groth, 1992). O sistema de reprodução pode ser tanto por autofecundação como por fecundação cruzada (Cronquist, 1981; Barroso, 1984; Ingrouille, 1992).

$\mathrm{O}$ fruto, à medida que amadurece, vai tendo a cor alterada e, quando atinge a plena maturação, apresenta deiscência explosiva, lançando as sementes para longe da planta-mãe (Barroso, 1984).

As sementes podem ser globosas, ovóides, cônicas, mais ou menos angulares, com 2,5 a $3 \mathrm{~mm}$ de comprimento por $2,5 \mathrm{~mm}$ de largura. Apresentam dois cotilédones e testa escura, marmorada ou não (Cronquist, 1981; Barroso, 1984; Kissmann \& Groth, 1992), sendo produzidas em grande quantidade e com pouca dormência. A causa da dormência não é conhecida, mas, luz aliada a temperaturas alternadas de 25 a $35^{\circ} \mathrm{C}$, estimulam a germinação (Kissmann \& Groth, 1992). As sementes germinam facilmente a uma profundidade de $4 \mathrm{~cm}$, ocorrendo, em lavouras de soja no Rio Grande do Sul e no Paraná, germinação escalonada (Kissmann \& Groth, 1992).

O ciclo da Euphorbia heterophylla L. é curto, sendo possível duas a três gerações em um ano. Essa espécie se desenvolve bem em quase todos os tipos de solo, preferindo, no entanto, os férteis e bem drenados. A via fotossintética do leiteiro é $\mathrm{C}_{4}$ e o número cromossômico básico é $2 \mathrm{n}=32$ (Kissmann \& Groth, 1992).

Nos últimos anos, vêm sendo observados genótipos de leiteiro resistentes em diversas lavouras no Rio Grande do Sul. A vasta área infestada pelo lei- 
teiro e o uso repetido de herbicidas altamente específicos com o mesmo mecanismo de ação para seu controle, podem ter criado situação favorável à seleção dos genótipos resistentes. A maior questão ecológica, associada à evolução da resistência aos herbicidas, envolve o entendimento das relações entre adaptação, freqüência gênica, herança e fluxo gênico (Maxwell $\&$ Mortimer, 1994).

O desenvolvimento das técnicas de cruzamentos e emasculação é fundamental para futuros estudos genéticos com o leiteiro, o que constitui o objetivo deste trabalho.

\section{MATERIAL E MÉTODOS}

Os experimentos foram realizados em vasos, em casa de vegetação do Departamento de Fitotecnia da Universidade Federal de Viçosa. O bloco de cruzamentos conteve dez plantas, sendo cinco de cada genitor. Para garantir a disponibilidade de pólen e flores receptivas no momento dos cruzamentos, realizaram-se duas semeaduras dos genitores, com intervalo de uma semana. Os genitores foram mantidos separados para evitar polinizações indesejadas.

Semearam-se quatro sementes por vaso, as quais foram submetidas a tratamento para quebra da dormência, cinco dias a $4-5^{\circ} \mathrm{C}$ em geladeira. Após a emergência, efetuou-se o desbaste, deixando-se uma planta por vaso, favorecendo o desenvolvimento de plantas ramificadas até com nove inflorescências.

Mediante observações prévias, determinaram-se quatro estádios da flor a estudar (Figura 1), durante os quais se realizavam as polinizações, transferindo-se o pólen das anteras do genitor masculino, com uso de pinça ou pincel, para o estigma da flor do genitor feminino. Nos estádios 1 e 2, em vista do pequeno tamanho das estruturas florais, as emasculações foram realizadas de dois a três dias após as polinizações; já nos demais estádios, antecederam as polinizações.

O processo de emasculação consistiu na retirada do invólucro, formado pelas brácteas fusionadas mais as flores masculinas, restando apenas a feminina. Após as polinizações e emasculações, nos estádios anteriores ao 3, foram feitas três vistorias diárias, para eliminação de novos estames que eram emitidos, uma vez que, nesses estádios, não é possível sua eliminação completa.

Depois dos cruzamentos e das emasculações, as inflorescências foram protegidas com saco plástico transparente, perfurado com agulha para evitar acúmulo de umidade no seu interior, envolvendo a inflorescência e as folhas da base. O saco plástico é importante por permitir a entrada da luz para as folhas da base da inflorescência, as quais parecem ter grande importância na formação das sementes.

Coletaram-se os ciátios usados nos cruzamentos no final do ciclo, ao iniciar a mudança da cor verde para a marrom, colocando-os para secar ao sol, em envelopes de papel, para liberação das sementes, que, posteriormente, foram limpas, acondicionadas em novos envelopes de papel e armazenadas em câmara seca.

\section{RESULTADOS E DISCUSSÃO}

Verificou-se que não há necessidade de se proceder à semeadura escalonada, em vista do longo período de emissão floral do leiteiro.

Os cruzamentos devem ser realizados a partir do estádio 2 (Quadro 1), quando os estigmas passam da cor avermelhada para a branca (Figura 1). Os resultados indicam que as polinizações no estádio 1 , além de apresentarem a menor percentagem de formação de frutos, também proporcionaram a maioria dos ciátios com uma ou duas sementes e raros com três, enquanto as realizadas após esse estádio propiciaram somente ciátios com três sementes. Considerando-se, também, que os estigmas passam de avermelhados para brancos a partir do estádio 2, pode-se supor que este seja o momento em que eles se tornam receptivos ao pólen.

Observa-se que, no estádio 1 , formou-se menos da metade do número total de sementes produzidas em qualquer um dos demais estádios. Portanto, 
flores polinizadas no estádio 2 ou após, garantem maior número de sementes por cruzamento e, além disso, podem ser emasculadas com maior facilidade. Contudo, na transição entre os estádios 3 e 4, quando a flor feminina já está visível, os estigmas apresentam brilho intenso e as anteras estão perto de ser emi- tidas, é que se realiza a emasculação com maior facilidade e eficiência, pelo tamanho mais adequado do ciátio e a facilidade de eliminação total das anteras.

No segundo dia após a polinização, já se pode distinguir o pegamento dos frutos. Posteriormente, ocorre alongamento do pedicelo, que posiciona o

Quadro 1. Número de frutos e sementes formadas, após hibridações controladas, em diferentes estádios de desenvolvimento floral de Euphorbia heterophylla L.

\begin{tabular}{|c|c|c|c|c|c|c|c|}
\hline \multirow{2}{*}{ Estádio } & \multirow{2}{*}{$\begin{array}{l}\text { Número } \\
\text { de flores }\end{array}$} & \multicolumn{2}{|c|}{ Frutos } & \multicolumn{3}{|c|}{ Sementes formadas por ciátio } & \multirow{2}{*}{$\begin{array}{l}\text { Total de } \\
\text { sementes } \\
\text { formadas }\end{array}$} \\
\hline & & & & 1 & 2 & 3 & \\
\hline & & n. ${ }^{\circ}$ & $\%$ & & & & \\
\hline $1 \ldots$ & 50 & 38 & 76 & 15 & 18 & 5 & $66 \mathrm{~b}$ \\
\hline $2 \ldots$ & 50 & 48 & 96 & 0 & 0 & 48 & $144 \mathrm{a}$ \\
\hline $3 \ldots$ & 50 & 46 & 92 & 0 & 0 & 46 & $138 \mathrm{a}$ \\
\hline $4 \ldots$ & 50 & 49 & 98 & 0 & 0 & 49 & $147 \mathrm{a}$ \\
\hline
\end{tabular}

(1) Médias seguidas por letras idênticas não diferem significativamente pelo teste de Duncan ao nível de 5\%.

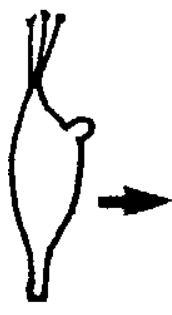

1

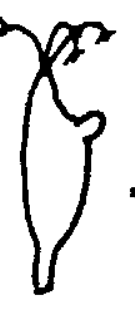

2

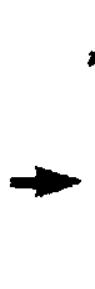

3

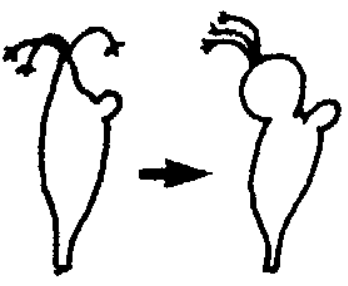

4

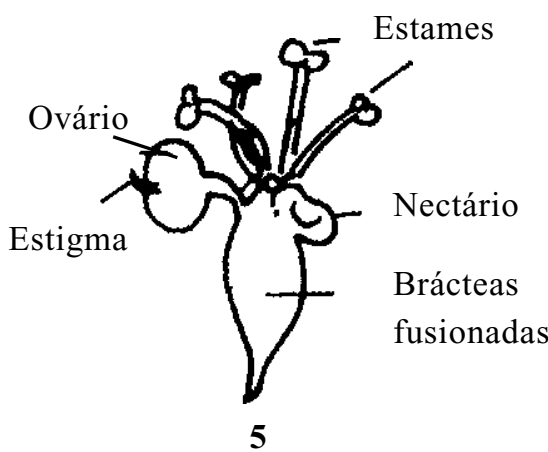

5

Figura 1. Estádios de desenvolvimento floral de Euphorbia heterophylla L. 1: Flores femininas apresentando estiletes separados, eretos e avermelhados; ovário incluso no ciátio; 2: Estiletes separados e pouco reflexos sobre o ciátio, com alteração da coloração avermelhada para branca, com a extremidade bifurcada; ovário ainda incluso no ciátio; 3: Estiletes separados e reflexos, brancos com brilho intenso; porção apical do ovário exposta; 4: Os estigmas apresentam coloração branca com brilho intenso, ovário totalmente exposto, emissão das primeiras flores masculinas; 5: Esquema de um ciátio. 
fruto de forma pendente ao lado oposto ao nectário. Caso a polinização não seja bem sucedida, pode-se polinizar a flor novamente, uma vez que os ciátios permanecem viáveis por dez a quinze dias, após o que são abortados.

A liberação de pólen pelas flores masculinas é maior com o aumento da temperatura, ocorrendo um pico sempre após o meio-dia, ao final da tarde.

O saco plástico usado para proteção dos cruzamentos também pode servir para recolher as sementes, evitando-se a necessidade de várias colheitas, já que a maturação dos ciátios é bastante desuniforme. Deve-se ter cuidado, caso haja cruzamentos distintos na mesma inflorescência, para não ocorrer mistura das sementes.

\section{CONCLUSÃO}

As polinizações dos ciátios de leiteiro realizadas a partir do estádio 2, momento em que os estiletes estão separados e pouco reflexos sobre o ciátio, alte- rando a coloração avermelhada para branca, com a extremidade bifurcada, ovário ainda incluso no ciátio, não afetaram o sucesso dos cruzamentos e o número de sementes formadas.

\section{REFERÊNCIAS BIBLIOGRÁFICAS}

BARROSO, G. M. Sistemática de angiospermas do Brasil. Universidade Federal de Viçosa, Viçosa, 1984. v.2, 377p.

CRONQUIST, A. An integrated system of classification of flowering plants. New York, Columbia University Press, 1981. 1262p.

INGROUILLE, M. Diversity and evolution of land plants. London, Chapman \& Hall, 1992. 340p.

KISSMANN, K. G. \& GROTH, D. Plantas infestantes e nocivas. São Paulo, Basf Brasileira, 1992. v.2, 798p.

MAXWELL, B. D. \& MORTIMER, A. M. Selection for herbicide resistance. In: POWLES, S. B. \& HOLTUM, J. A. M. Herbicide resistance in plants: biology and biochemistry. Boca Raton, CRC Press, 1994. p.1-25. 